Central Washington University

ScholarWorks@CWU

All Faculty Scholarship for the College of the Sciences

$10-30-2018$

Ground-truthing social vulnerability indices of Alaska fishing communities

Anna Lavoie

Kim Sparks

Stephen Kasperski

Amber Himes-Cornell

Kristin Hoelting

See next page for additional authors

Follow this and additional works at: https://digitalcommons.cwu.edu/cotsfac

Part of the Aquaculture and Fisheries Commons, Natural Resources and Conservation Commons, Natural Resources Management and Policy Commons, and the Oceanography Commons 


\section{Authors}

Anna Lavoie, Kim Sparks, Stephen Kasperski, Amber Himes-Cornell, Kristin Hoelting, and Conor Maguire 


\title{
Ground-truthing social vulnerability indices of Alaska fishing communities
}

\author{
Anna Lavoie ${ }^{\mathrm{a}, \mathrm{b}}$, Kim Sparks ${ }^{\mathrm{a}, \mathrm{b}}$, Stephen Kasperski ${ }^{\mathrm{b}}$, Amber Himes-Cornell ${ }^{\mathrm{c}}$, \\ Kristin Hoelting ${ }^{d}$, and Conor Maguire ${ }^{\mathrm{e}}$ \\ ${ }^{a}$ Pacific States Marine Fisheries Commission, Portland, Oregon, USA; ${ }^{b}$ Alaska Fisheries Science Center, \\ NOAA, National Marine Fisheries Service, Seattle, Washington, USA; 'CAMURE/LABEX/IUEM, Université de \\ Bretagne Occidentale, BREST Cedex 3, France; ${ }^{\mathrm{d} H u m a n}$ Dimensions of Natural Resources, Colorado State \\ University, Fort Collins, Colorado, USA; ${ }^{\mathrm{e} C u l t u r a l}$ and Environmental Resource Management, Central \\ Washington University, Ellensburg, Washington, USA
}

\begin{abstract}
Community vulnerability is increasingly evaluated through quantitative social indices, typically developed using secondary data sources rather than primary data collection. It is necessary to understand the validity of these indices if they will be used to inform policy and decision making. This paper presents a ground-truthing effort to validate quantitative indices that characterize the well-being of Alaska fishing communities. We utilized ethnographic data collected from 13 representative communities and a capital assets framework to ground-truth the indices, in which qualitative ranks of vulnerability were compared against quantitative indices. The majority $(73.8 \%)$ of ranks were in complete or moderate agreement and the results indicate that most of the indices are representative of community vulnerability; yet some variables utilized to create the indices could be modified to better reflect realities in Alaska. Indices of commercial fishery engagement and reliance appeared to be more reliable than socio-economic indicators, particularly for smaller fishing communities. We also confirmed that the indices do not capture political, or ecological factors that affect levels of community vulnerability. We conclude that quantitative indices of community vulnerability are useful rapid assessment tools; however, they should be validated, and complemented with ethnographic data prior to their implementation as policy making and management tools.
\end{abstract}

\section{KEYWORDS}

Alaska fishing communities; ground-truthing; social indices; social vulnerability; well-being

\section{Introduction}

In recent years, researchers have increasingly emphasized the importance of indicators for measuring and monitoring socio-ecological change (Hicks et al. 2016). Quantitative indices serve as proxies for social phenomena by condensing complex information into measurable outcomes that are informative to policy-makers and resource managers (Boyd and Charles 2006; Cutter, Boruff, and Shirley 2003; Hicks et al. 2016; Leslie et al. 2015). Secondary datasets, such as U.S. Census data, have been used for developing such indicators for fishing communities to minimize costs associated with collecting 
ethnographic data (Blount et al. 2015; Colburn et al. 2016; Himes-Cornell and Kasperski 2016; Jacob et al. 2010; Pollnac et al. 2015; Sepez et al. 2006). However, when using secondary data to develop indicators, the question of validity arises; do the indicators represent on-the ground realities and processes? Caveats of using secondary data, such as U.S. Census data, include inherent discrepancies of the data from inconsistent documentation and unreliable reporting. Indicators based on these data also may not reflect on-the-ground complex social phenomena, such as power relations related to resource access and use (Lyons, Carothers, and Reedy 2016). Quantitative indices typically developed using statistical methods that aggregate data into generalized factors are interpreted as indicators of social vulnerability and well-being, but they may or may not accurately reflect complex socio-economic processes that affect vulnerability (Eakin and Luers 2006; Jacob et al. 2010; Oulahen et al. 2015).

To address these caveats, researchers have developed various methodologies for testing, or "ground-truthing," the validity of social indices (Blount et al. 2015; HimesCornell et al. 2016; Jacob et al. 2013; Oulahen et al. 2015; Pollnac et al. 2015; Smith et al. 2011). The use of multiple methodologies to test validity of data, known as triangulation or ground-truthing, is necessary to confirm findings and fully evaluate any indicators that may be used to inform policy. Agreement between multiple, independent viewpoints, or sources, should ensure validity and reliability (Bitsch 2005; Jick 1979). Ethnography is a common method applied in ground-truthing and triangulation processes focused on community-level assessments because it is often based on grounded knowledge, where local processes and phenomenon are described by participants (Bitsch 2005; Hay 2010). Agreement between ethnographic assessments and quantitative indicators can improve validity and reliability, whereas disagreement suggests that the indicators may not properly represent the community conditions, or the methods applied need evaluation. In this sense, ethnographic research is fundamental to teasing out complex contextual nuances and historical processes that might be otherwise overlooked, or may not be accounted for in broadly collected objective quantitative data. This is particularly important for socio-economic fisheries research given the diverse contexts of small and large-scale fisheries and the importance of fisheries to human well-being in the United States and around the globe.

The National Oceanic and Atmospheric Administration's National Marine Fisheries Service (NOAA Fisheries) has recently developed social and fisheries engagement indices to evaluate fishing community vulnerability at both national and regional scales (Himes-Cornell and Kasperski 2015, 2016; Himes-Cornell et al. 2016; Jacob et al. 2013; Jepson and Colburn 2013). The indices were developed to inform fisheries policy and management implemented under the Magnuson-Stevens Fishery Conservation and Management Act (MSFCMA) and to better identify impacts to fishery-dependent communities. Specifically, principal component factor analysis (PCFA) was utilized to calculate the social indices in order to develop community typologies based on fishery engagement (i.e., landings and revenue), and socio-economic variables drawing from U.S. Census data (Himes-Cornell and Kasperski 2015, 2016; Himes-Cornell et al. 2016; Jacob et al. 2013; Jepson and Colburn 2013). The indices can inform management in making decisions that avoid or reduce impacts to highly vulnerable, and or fisherydependent communities. However, the indices are derived from secondary data raising 
the question of how well they represent fishing community well-being and vulnerability. As a result steps have been taken to validate, or ground-truth the social indices at NOAA Fisheries, in addition to researchers in other areas applying similar methods.

Existing research that validates community social indices through ground-truthing is novel, but limited. Studies have validated typologies of communities that were developed based on community vulnerability scores (Pollnac et al. 2015; Smith et al. 2011), validated coarse indicators of fishing dependence by comparing quantitative and subjective ranks of communities (Jacob et al. 2010), or reduced contextual ethnographic data of community vulnerability for quantitative analysis (Blount et al. 2015). HimesCornell et al. (2016) present a rapid appraisal methodology designed to better understand the appropriateness of indicators (input variables) used to create well-being indices for Alaska. The authors measured reliability of the indicators used to develop the quantitative indices, and construct validity of levels of community vulnerability based on the quantitative indices. The authors concluded that the indicators were generally reliable; however, the quantitative vulnerability indices derived from these indicators for the communities were not fully consistent with researcher subjective rankings of communities based on field-work. The findings reveal that quantitative indices and their validation require more comprehensive site-specific context.

In this paper, we build upon these previous efforts by focusing on validating revised vulnerability indices (Himes-Cornell and Kasperski 2016) through qualitative analysis of contextual ethnographic data. Our work contributes to scholarship advancing the use of social indicators for assessing fishing community vulnerability and well-being and serves three purposes, that is, to: (1) qualitatively ground-truth quantitative indices of Alaska fishing community vulnerability developed from secondary data; (2) present factors which affect levels of vulnerability of Alaska fishing communities drawing from ethnographic data; and (3) advance a community vulnerability framework that can improve community vulnerability indicator selection and ground-truthing projects. We demonstrate that quantitative social indices are useful rapid assessment tools for fishery management; however, to the extent possible indices should be validated and complemented by ethnographic data to increase their accuracy as policymaking and management tools.

\section{Community vulnerability}

The concept of community vulnerability relative to environmental change has largely evolved from hazards and disaster research concerned with social and ecological susceptibility to harm and risk management (Adger 2006; Blaikie et al. 1994; Cutter, Boruff, and Shirley 2003). The concept has evolved in a variety of disciplines that have slightly different conceptualizations of vulnerability depending upon the context in which it is applied (Eakin and Luers 2006). Given the various definitions and applications of community vulnerability, researchers have argued that vulnerability is a complex theoretical concept and is difficult to conceptualize and measure in any one specific way (Adger 2006; Alwang, Siegel, and Steen 2001; Eakin and Luers 2006; McLaughlin and Dietz 2008; Turner et al. 2003). Nevertheless, the majority of researchers have drawn from the definition originating in hazards research, defined as "the degree to which ... systems are susceptible to, or unable to cope with adverse effects of change" (Schneider et al. 2007). Scholars have 
extended the definition to include an individual or system's exposure to risk or change, sensitivity to shocks, and level of adaptive capacity, or resilience, to withstand shocks and change (Adger 2006; Clark et al. 2000; Miller et al. 2010).

Our conceptualization of community vulnerability draws from this background and is situated within the components of Turner et al.'s framework (2003), in which the complex interaction of social, ecological, political, economic, and cultural factors affect wellbeing (Adger 2006; Turner et al. 2003). In this context, well-being is broadly defined here as a community's level of health, prosperity, and happiness (Pollnac et al. 2006), given that community vulnerability cannot be assessed based only on economic terms (Adger 2006).

More specifically, levels of vulnerability and relative well-being can be determined by assessing entitlements or the available stocks of capital an individual, household, or community has that can be mobilized for producing sustainable livelihoods and increasing adaptive capacity (Adger 2006; Allison and Ellis 2001; Bebbington 1999; Eakin and Luers 2006; Rakodi 1999; Scoones 1998, 2009; Turner et al. 2003). While not necessarily exclusive, five capital asset categories have emerged from sustainable livelihoods scholarship: financial, human, social, natural, and physical (DFID 1999). This capital assets framework has been applied in sustainability science and disaster research to assess poverty and resilience (Bebbington 1999; DFID 1999; Mayunga 2007; Scoones 1998); however, it has been under-utilized as a tool for selecting variables to develop indicators of community vulnerability and well-being (Adger 2006; Eakin and Luers 2006). Other frameworks for selecting social indicators tend to be more coarse or over-generalized (Boyd and Charles 2006).

The capital assets framework can be used to assess tangible and intangible (social capital) factors and processes that influence well-being and levels of vulnerability, and can be both place-specific and transferable across contexts (Adger 2006; Eakin and Luers 2006). More significant, in terms of assessing community well-being and vulnerability, is the inclusion of social capital in the framework. Social capital, networks, social norms, leadership, learning, and access to political power are significant factors that affect community well-being and social vulnerability (Cutter, Boruff, and Shirley 2003; Miller et al. 2010). A great deal of scholarship has demonstrated the significance of social capital in fishing communities for fisheries management (Acheson 1988; Gutierrez, Hilborn, and Defeo 2011; Isham 2000; Marín and Berkes 2010; Marín et al. 2012; Sekhar 2007), and for increasing social adaptive capacity (Adger 2010; Bodin and Crona 2008; Gutierrez, Hilborn, and Defeo 2011; Newman and Dale 2005; Olsson, Folke, and Berkes 2004; Plummer and FitzGibbon 2007; Pretty 2003; Sekhar 2007). These social processes, unaccounted for in US Census data, highlight the importance of primary data collection for a holistic assessment of community vulnerability and well-being which includes validating indices developed from secondary data sources.

Himes-Cornell et al. (2016) undertook a first step in ground-truthing quantitative vulnerability indices of Alaska fishing communities by conducting a rapid validation assessment. The aim of this paper is to advance the previous work with contextual analysis, given that the previous effort was unable to effectively capture social or political aspects of community well-being. Therefore, we utilize the capital assets framework to capture socio-cultural and political processes and structure ethnographic data into 


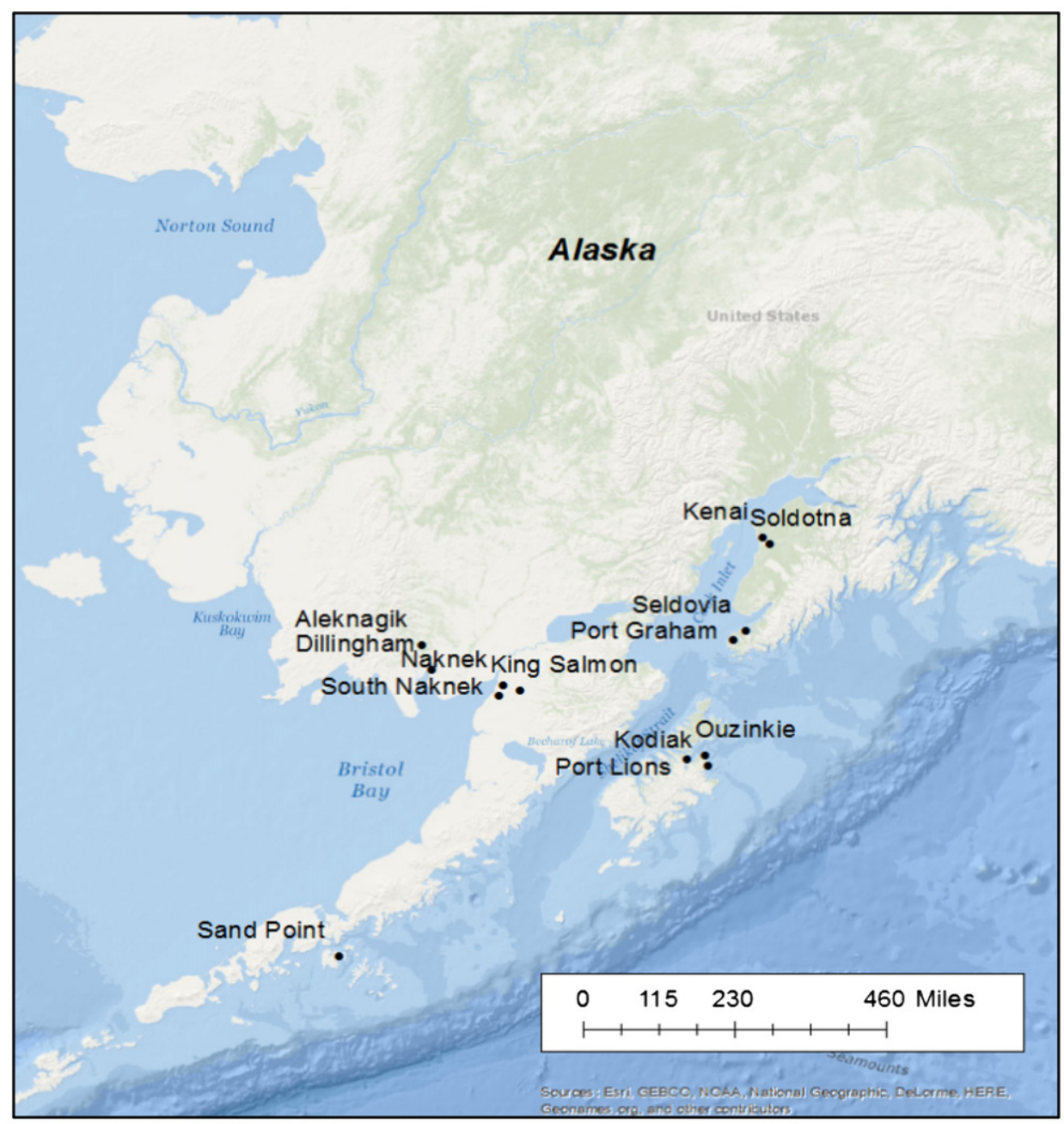

Figure 1. Map of communities selected for ground-truthing social indices.

categories of factors that affect community well-being that are related to the quantitative indices. The framework provides a robust and efficient method for structuring ethnographic data into a format for ease of validation.

\section{Methodology}

\section{Data collection}

The Alaska fishing community social vulnerability indices we validated in this groundtruthing exercise are presented in detail in Himes-Cornell and Kasperski (2016). In this previous work, the indices were created via PCFA, which allowed for rapid generation of standardized indices, using input variables from U.S. Census Bureau data and Alaska Department of Fish \& Game fishery data (ADF\&G). This methodology followed previous standardized methods for developing indices of community vulnerability and wellbeing at the regional and national scales (Cutter, Boruff, and Shirley 2003; Jacob et al. 
Table 1. Capital asset categories with example metrics of vulnerability.

\begin{tabular}{ll}
\hline Capital & \multicolumn{1}{c}{ Example Metrics } \\
\hline Financial & Sources of income; level of economic diversity; investment and savings \\
Human & Population composition; available labor force; quality of education; health; quality of life \\
Natural & Access to natural resources; quality/health of natural resources; dependence on natural resources \\
Physical & Infrastructure including housing; water; transportation; access to goods and services \\
Social & Social cohesion; networks and connectedness; shared culture; rules and norms \\
Political & $\begin{array}{l}\text { Policy that supports or constrains livelihoods and access to natural resources; ability to partici- } \\
\text { pate in political process; government leadership that supports or detracts from growth and } \\
\text { development. }\end{array}$ \\
\hline
\end{tabular}

Metrics are not exhaustive and are drawn from various sources (Boyd and Charles 2006; Cutter, Boruff, and Shirley 2003; DFID 1999).

2013; Jepson and Colburn 2013), but the input variables were adapted for relevance to Alaska communities. For example, Alaska residents rely upon subsistence fishing and ADF\&G collects and manages subsistence fishery harvests.

For Alaska communities, the PCFA resulted in seven social vulnerability indices and seven fisheries participation indices. The calculated community vulnerability index scores were then utilized to run a cluster analysis that allowed selection of thirteen community typologies, with varying scores, in which to conduct ethnographic fieldwork (Figure 1). The resident population of the communities in 2013, the year in which field work was conducted, ranged from 7,251 in Kenai to 57 in the small community of South Naknek. A detailed description of ethnographic data collection, including the number of interviews conducted per community, is available in Himes-Cornell et al. (2016). In summary, semi-structured interviews were conducted between May and September of 2013 in each community, and interviewers used a series of prompting topics that allowed respondents flexibility in answering the questions, which would best represent their communities and not the bias of the researchers. Respondents were broadly asked to characterize their community, describe any current concerns, how the community has changed in recent years, describe community strengths and weaknesses, and discuss the importance of fishing to the community. A total of 286 interviews were completed.

\section{Data analysis and ground-truthing}

We analyzed the ethnographic interview data using Atlas.ti software, via inductive coding where themes emerged from the content of the data (Saldana 2009). Specifically, we first coded data via descriptive "in vivo" coding in which codes are created based on respondent's statements. Next, through an iterative process, we further refined the data with "analytic codes" based on relevant themes that emerged from the data (Hay 2010) to reflect a cohesive interpretation of community vulnerability and well-being. Interviews were largely analyzed by community; however, there were many overarching themes related to community vulnerability that broadly applied to all communities.

We then utilized a capital assets framework (DFID 1999; Mayunga 2007) (see Table 1) and applied the coding results to the framework by creating a table to summarize the ethnographic data by capital asset category and community as shown in Table 2 . The table served as a tool to summarize factors, derived from the ethnographic data, that contribute to, or detract from, community vulnerability. For example, codes such as 


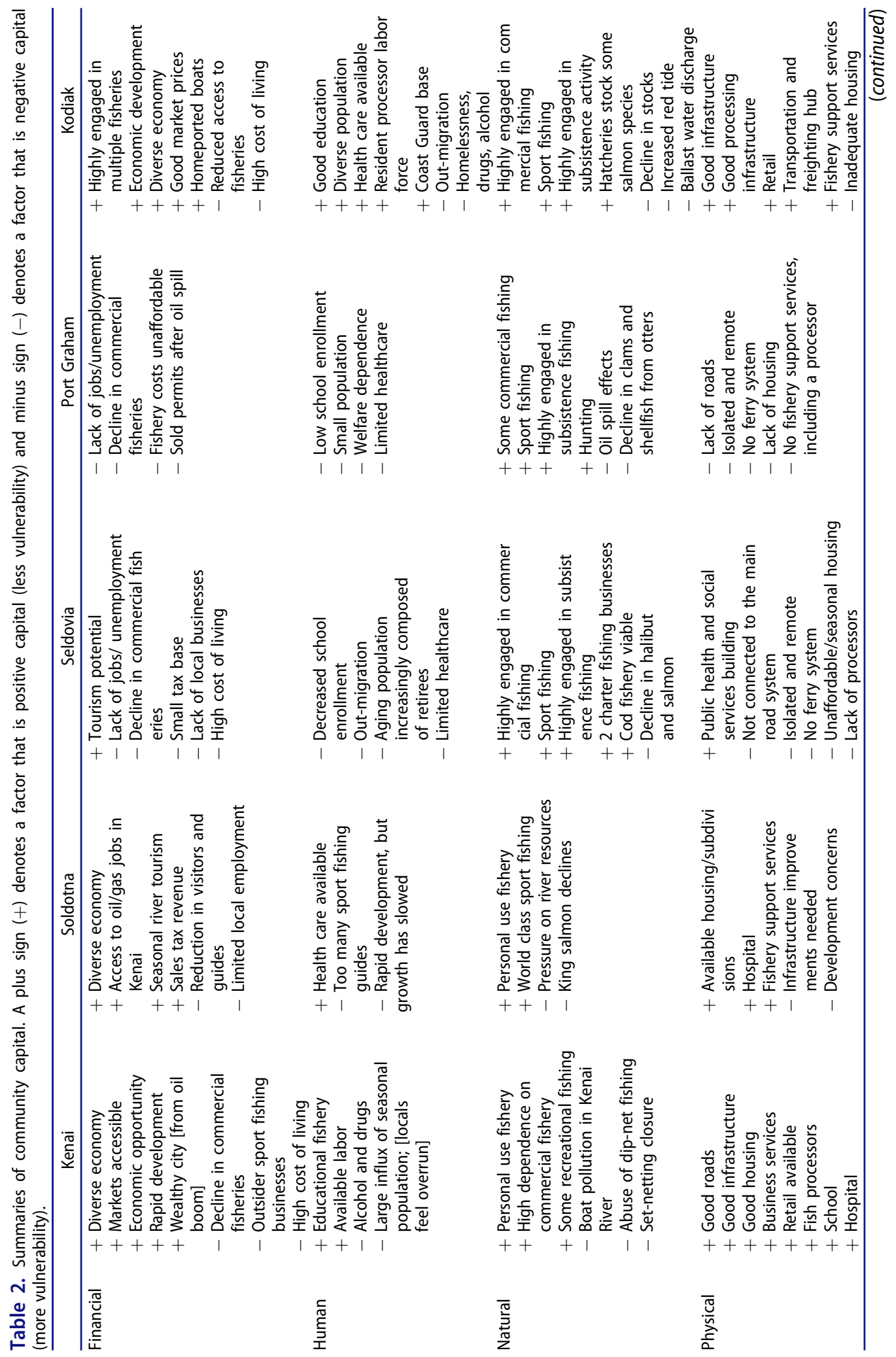




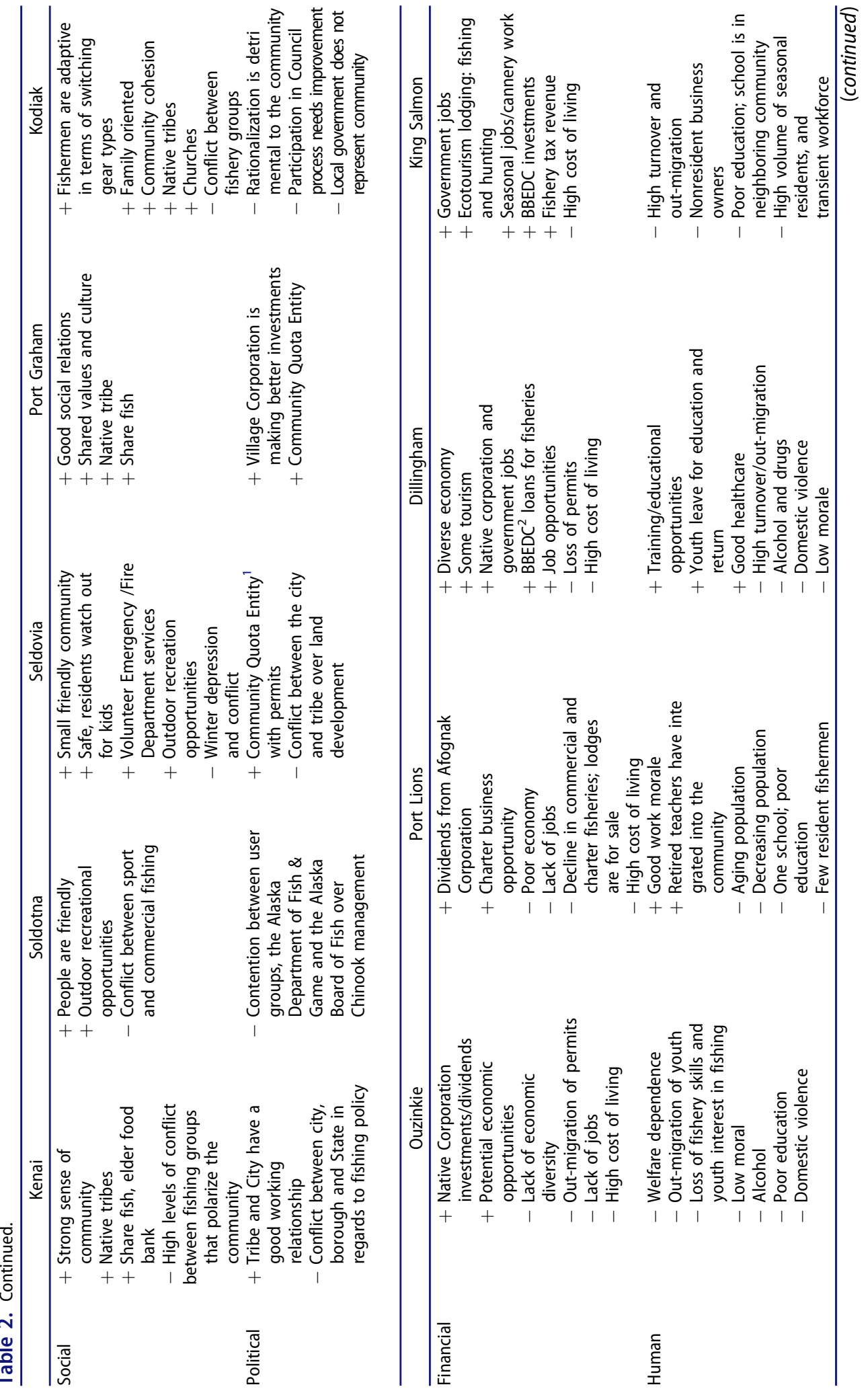




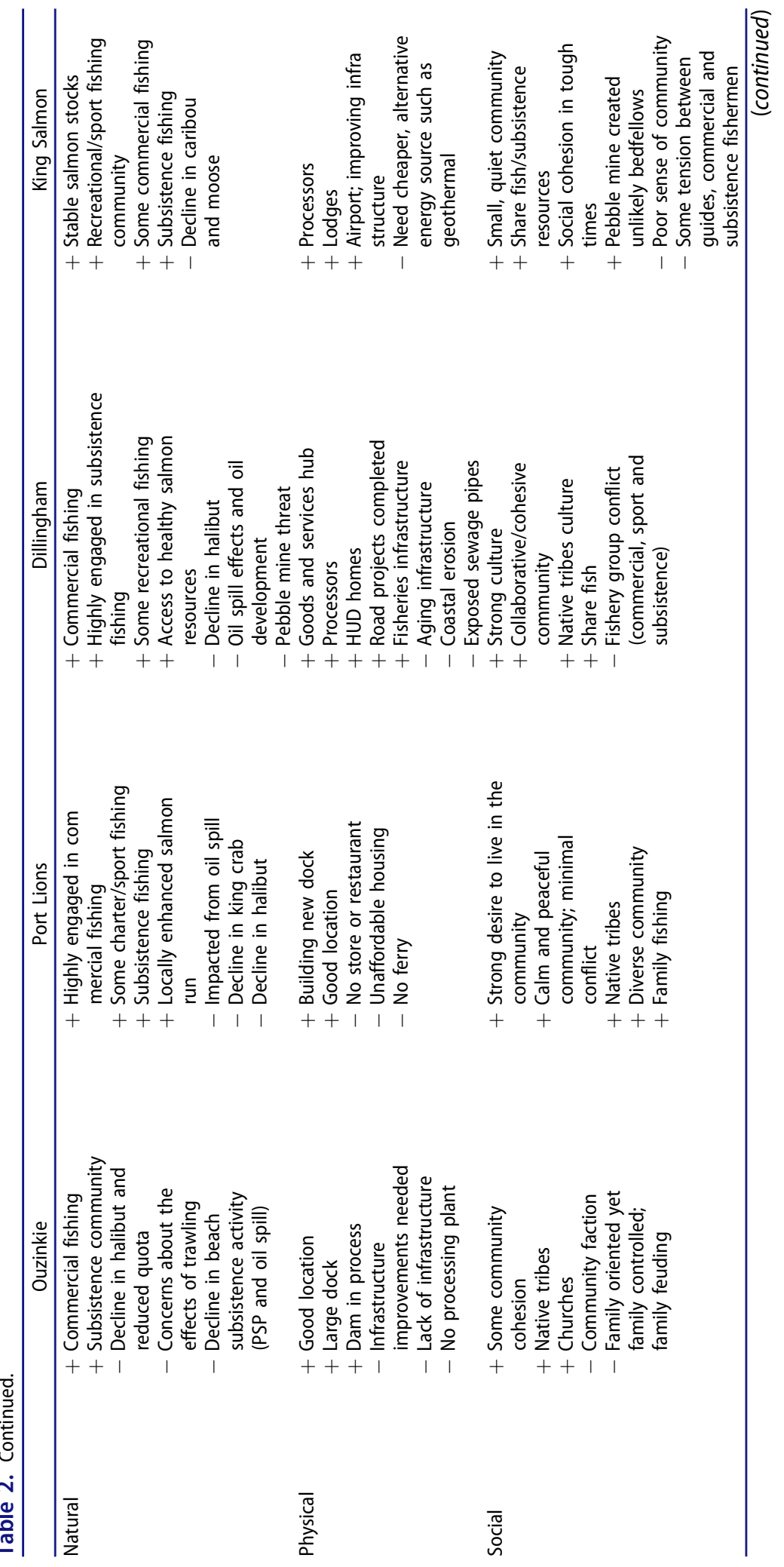




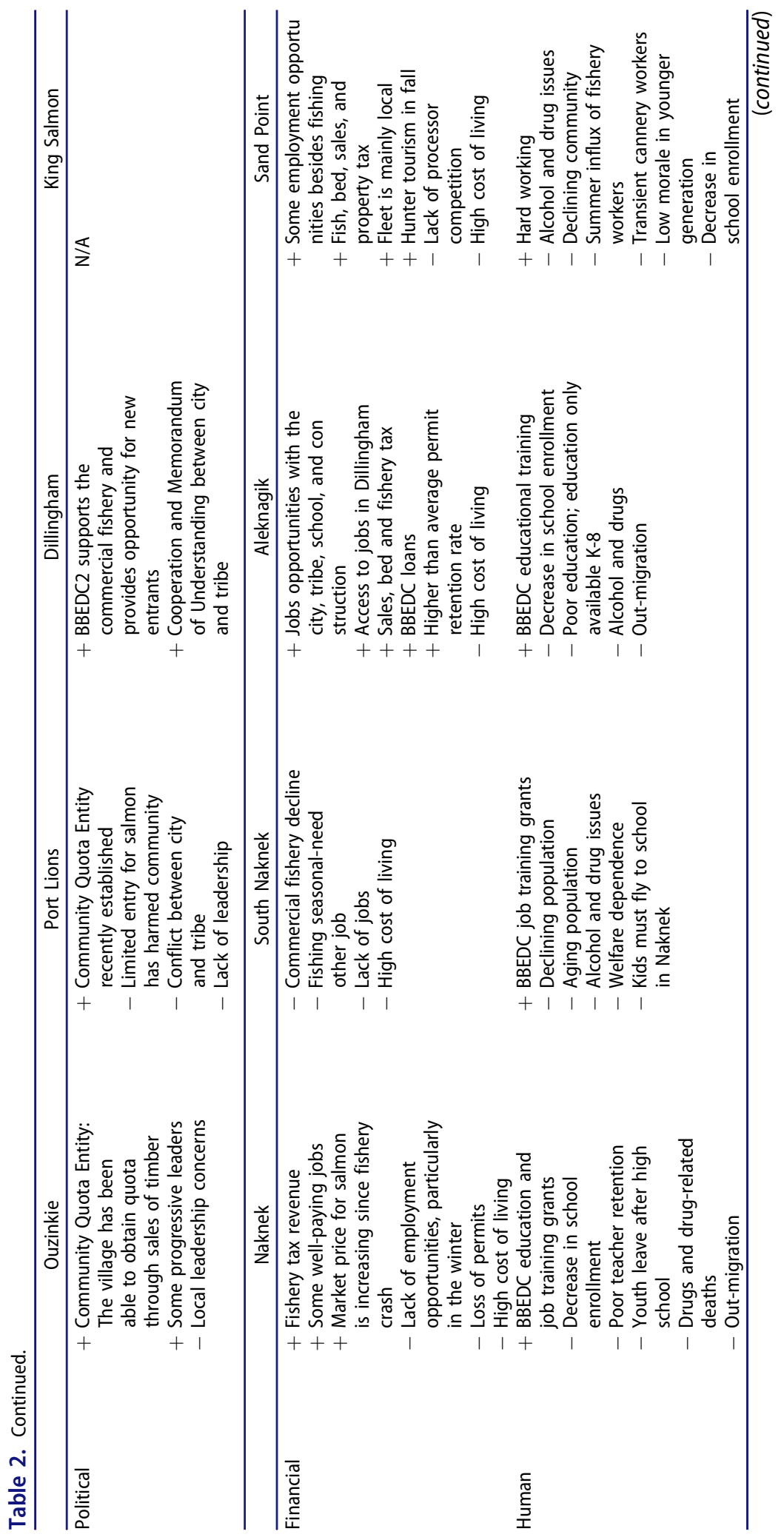




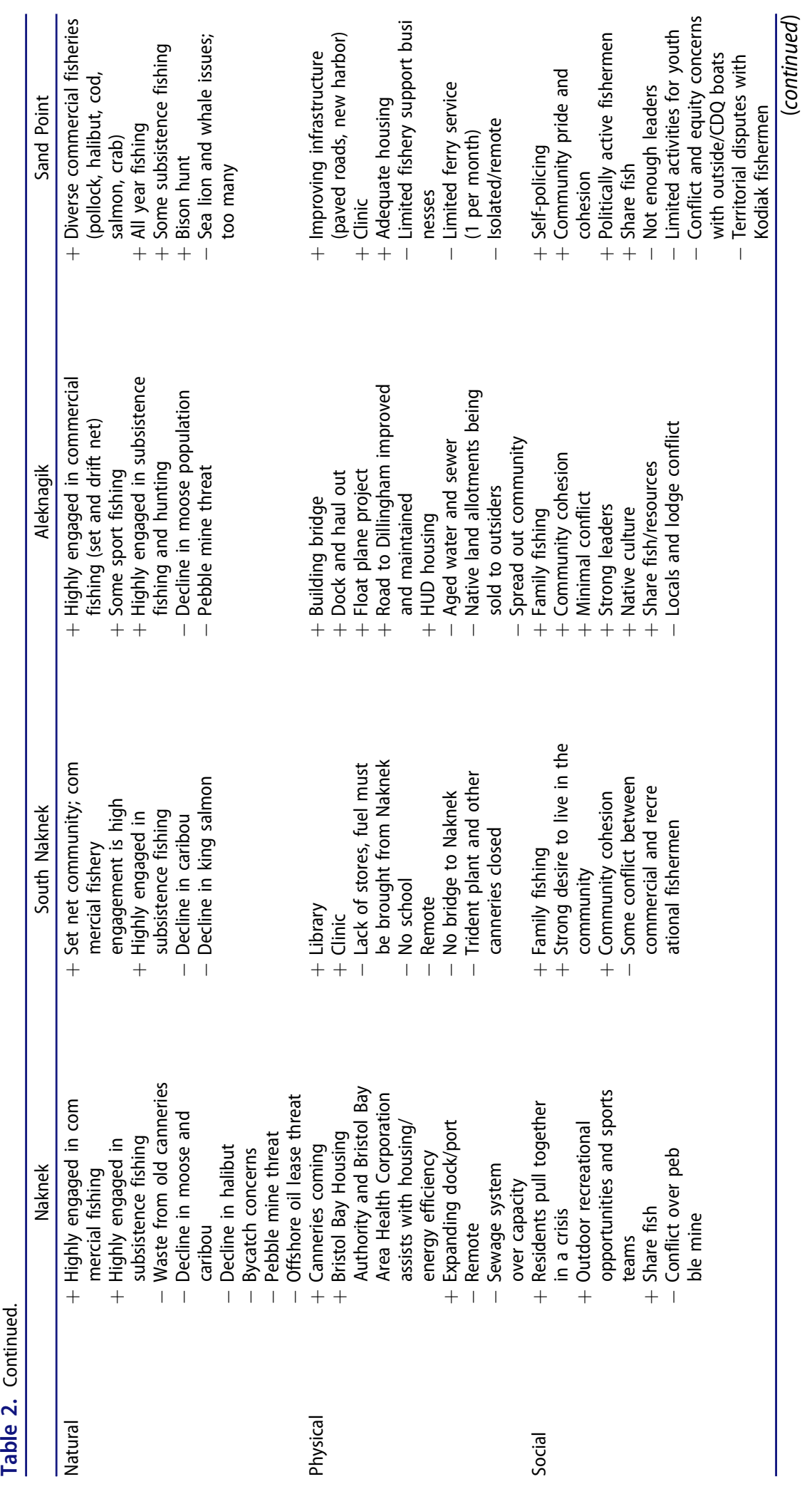




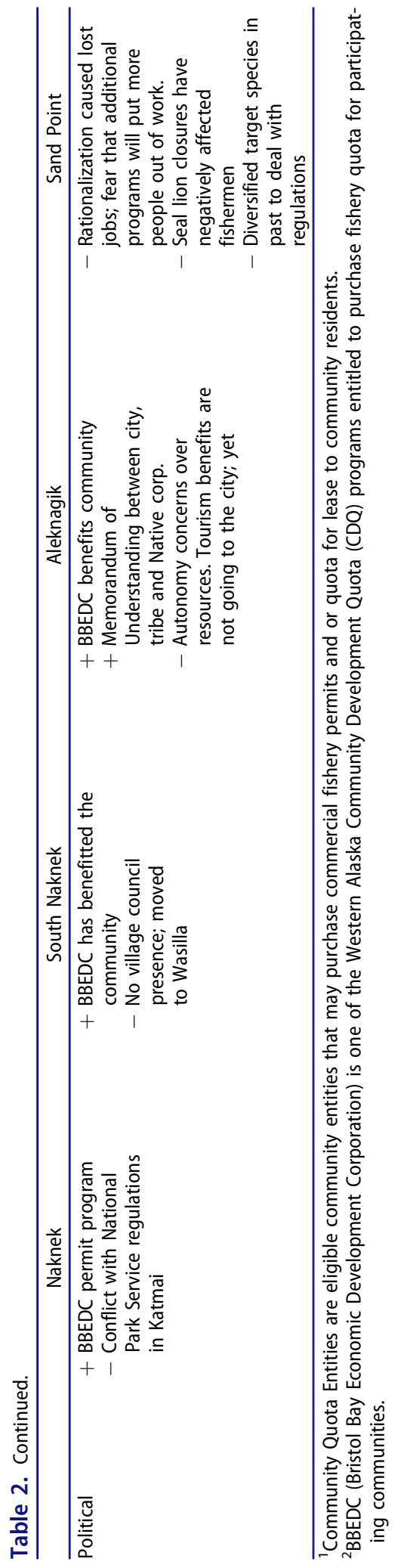


Table 3. Social and fisheries participation indices validated from HimesCornell and Kasperski (2016).

\begin{tabular}{ll}
\hline Social Indices & Fisheries Participation Indices \\
Personal disruption & Commercial fishing engagement \\
Poverty & Commercial fishing reliance \\
Labor force structure & Recreational fishing engagement \\
Housing characteristics & Recreational fishing reliance \\
Housing disruption & Subsistence fishing involvement \\
\hline
\end{tabular}

"diverse economy" were listed in the financial capital category, whereas "available labor" was listed under human capital. We added a political capital category to illustrate that any discussion of community well-being would be incomplete without formally recognizing the role of policy in resource allocation. This became more prevalent during data analysis since political statements were prominent in the data. As Adger (2006, 270) succinctly states, "vulnerability is driven by inadvertent or deliberate human action that reinforces self-interest and the distribution of power in addition to interacting with physical and ecological systems." As such, political efficacy is treated as an asset that is mobilized rather than an external process. The capital assets table was generated through researcher immersion in the data, as part of the analysis of each community. There were not sufficient data to create a separate category of cultural capital; therefore, codes capturing cultural aspects were included in the social capital category. We included supportive and illustrative quotes of dominant themes from the data to ground the framework (Appendix Table A1).

In populating the capital assets data Table 2 we included a plus or a minus categorization to differentiate between positive and negative capital, and potential sources of vulnerability for each entry as has been conducted elsewhere (Cutter, Boruff, and Shirley 2003; Oulahen et al. 2015). Categorization of $+/$ - criteria was based on the language of respondents, as well as literature on capital assets in relation to vulnerability and well-being. For example, those communities that indicated they had a diverse economy were assigned a positive sign (“+ diverse economy” was entered into the table under the category financial capital for that community), considering that a diverse economy is generally more stable and less susceptible to perturbations (Cutter, Boruff, and Shirley 2003).

To prepare the quantitative social indices for ground-truthing, we developed rankings from community vulnerability scores generated from the PCFA that was previously conducted in (Himes-Cornell and Kasperski 2016). Each quantitative index provides normalized factor scores for each community, such that 0 equals the mean, and the community scores represent the standard deviation from the mean. The higher the score, the higher the level of vulnerability for that index. We therefore converted the numeric community scores to low $(\leq 0)$, medium (0-.49), medium high (.50-.99), and high $(\geq 1)$ ranks per index, consistent with NMFS National social vulnerability reporting (http://www.st.nmfs. noaa.gov/humandimensions/social-indicators/map). Next, drawing from our ethnographic data analysis, we subjectively ranked the vulnerability indices for each community as low, medium, medium high, or high. The qualitative rankings were then compared against quantitative rankings for each of the indices (Table 4 of the results). For example, if the community PCFA score was low and the qualitative rank was low, they are in complete agreement. If the PCFA score was low and the qualitative rank medium, or medium and 


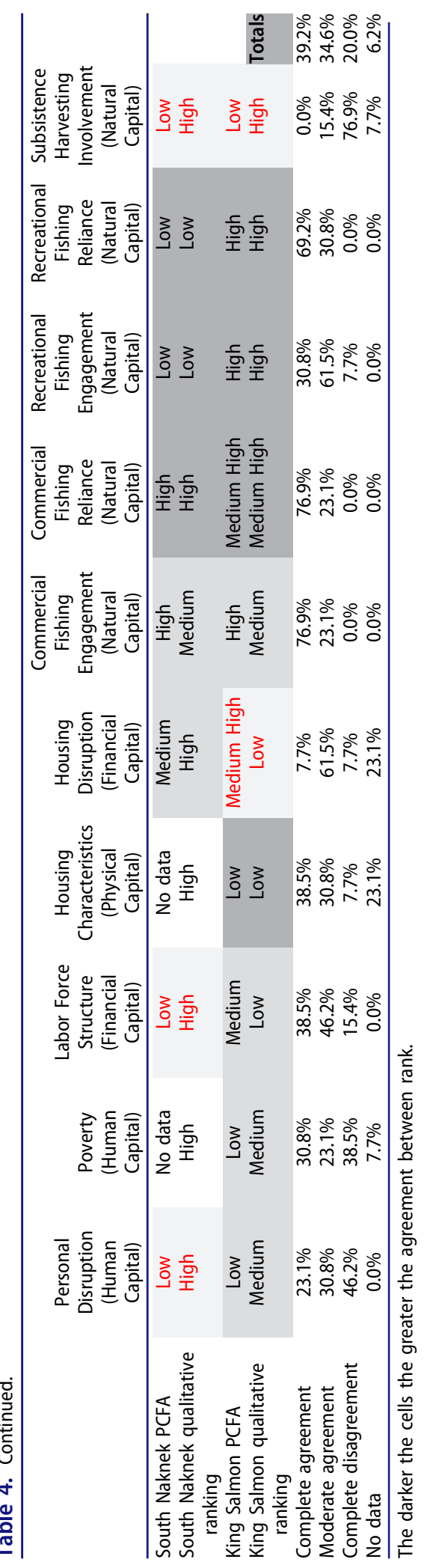


high, respectively, they are in moderate agreement. If the PCFA score was low and the qualitative rank high, or vice versa, they are in complete disagreement.

Only 10 of the original 14 quantitative indices in Himes-Cornell and Kasperski (2016) were validated because there were not sufficient qualitative data to support validation of four indices (population composition, status of schools, commercial processing engagement, and commercial processing reliance) (see Table 3 for the list of indices validated). In other words, respondents did not sufficiently elaborate on these aspects within their communities in the interviews.

\section{Results}

\section{Ground-truthing social vulnerability scores}

The majority $(73.8 \%)$ of the quantitative community ranks were in complete agreement (39.2\%) or moderate agreement $(34.6 \%)$, and $26.2 \%$ were in complete disagreement with qualitative ranks, or lacked data to compare (Table 4). The most uniform rankings were the with the commercial fishing engagement and commercial fishing reliance indices (10 of 13 communities with equal rankings), and recreational fishing reliance ( 9 of 13 communities with equal rankings). Specifically, for commercial fishing engagement, there was slight disagreement for the rankings of Soldotna, South Naknek, and Sand Point in which the quantitative ranks were high engagement and qualitative ranks were medium engagement. For commercial fishing reliance, the Kenai quantitative ranking was slightly lower (medium) than the qualitative rank (high), Ouzinkie and Dillingham quantitative ranked slightly higher (high) than the qualitative rank (medium and medium high, respectively), and the Sand Point quantitative rank was slightly lower (medium high) than the qualitative rank (high). Of the recreational fishing rankings, the quantitative rank for Seldovia was medium, whereas the qualitative rank was medium-high, Ouzinkie and Naknek quantitative ranks were medium and the qualitative ranks were low, and Port Lions quantitative rank was high and the qualitative medium.

The index with the highest level of disagreement between quantitative and qualitative rankings was subsistence fishing involvement, as 10 of the 13 communities showed high disagreement. Only Kenai and Kodiak rankings were in close agreement, even though both still had lower quantitative ranks than the qualitative ranks. Soldotna's qualitative rank was not compared given the lack of data needed to include it in the quantitative analysis. The ethnographic data demonstrates that subsistence fishing involvement is much higher than suggested by the quantitative index, which will be examined more carefully in the discussion section. In addition, there was high disagreement of rankings for personal disruption and poverty of Seldovia, Ouzinkie, Port Lions, Naknek, and South Naknek. The ethnographic data suggests that these communities are highly vulnerable in terms of these indices and this may not be reflected by the quantitative results.

The communities that demonstrated the highest agreement between quantitative and qualitative rankings of the indices were Kodiak ( 8 of the 10 rankings were equal) and Kenai (6 of 10 rankings were equal). The remaining communities had five indices or 
less with equal rankings. Port Lions had the highest disagreement between ranks as there was high disagreement of six indicators.

\section{Ground-truthing in context}

Factors that affect community vulnerability vary and each community has unique histories and characteristics. These factors are based upon the interviews conducted in each community and provided the basis for the qualitative ranks of the indices for each community. There are also common trends across communities, as demonstrated in Table 2. Prominent trends across communities include reliance upon subsistence resources to supplement livelihoods, high cost of living, out-migration, lack of economic opportunity, and decreased opportunity in commercial fishing. Social factors, such as conflict and social capital also may increase or decrease a community's vulnerability, and these are not reflected in the quantitative indices, yet are common across communities. In addition, compromised resources such as reduced salmon stocks, particularly Chinook, and oil spill pollution decrease the availability of subsistence resources that communities heavily rely upon, increases community vulnerability.

Subsistence fishing for salmon was significantly important to all communities in this study. It is particularly critical for smaller communities with fewer available jobs, yet all communities rely upon subsistence fishing as a livelihood supplement, for food security, and culture. Many communities are remote and do not have sufficient infrastructure for accessing affordable grocery stores. With the high cost of living, subsistence fishing is often how people get by and provides food during winter when fishing activity is slow. Subsistence fishing contributes to community well-being by providing food resources on a regular basis, which is even more critical during periods of economic decline. It is also a way of life and an important part of local culture regardless of community size. This includes community sharing of subsistence resources, including elder programs, which reinforces community social networks and cohesion.

Respondents across all communities remarked that cost of living in rural Alaska is prohibitively high. High costs permeate all facets of life including housing costs, utilities such as electricity and heating oil, cost of food, and cost of fuel which affects travel, access to goods, as well as fishing activity. Respondents reported that in the past they would frequently fly to Anchorage to pick up supplies, but more recently the trip cost has been prohibitive. Increasing costs have impacted the availability of ferry, barge and airline services, and the ability of residents to access these services. Larger communities that have sufficient infrastructure, such as Kodiak, Kenai, and Dillingham, are better positioned to support fishing activities and provide services to other communities (Kent and Himes-Cornell 2016; Lyons, Carothers, and Reedy 2016). Some communities lacked ferry service or service was infrequent (i.e., once per month), which diminishes resident's ability to access essential goods, supplies, and services. The lack of infrastructure and transportation also increases their vulnerability because of the limited ability to evacuate in the event of a natural disaster, as has been emphasized elsewhere (Cutter et al. 2008).

Lack of economic opportunities was a major theme for the communities of South Naknek, Port Graham, Ouzinkie, Port Lions, Aleknagik, Seldovia, and Soldotna. 
Respondents expressed concern that many communities lacked job opportunities that would allow residents to remain in communities. Issues arose about not having options to supplement a bad fishing season. Ultimately, lack of employment was a limiting factor to retaining existing residents; permanent out-migration, welfare, and/or seasonal migration for work were reported as the options available for communities with stagnant economies. These smaller communities are more vulnerable because they have limited options for earning income and are more at risk to political and environmental shocks as recovery from shocks take more time (Cutter, Boruff, and Shirley 2003).

Migration was also a particular issue for smaller communities that were heavily dependent on fisheries, such as Seldovia, Port Graham, Port Lions, South Naknek, Naknek, Ouzinkie, and Aleknagik, as has been demonstrated elsewhere (Donkersloot and Carothers 2016). Out-migration occurred where there are limited job alternatives to fishing. Some migration is seasonal, as residents seek work in other communities, and others move where jobs are located. Extensive out-migration leads to reduced services, including school closures and this leads to a vicious cycle in which the community cannot attract new residents. Many respondents stated "the loss of a school is the death of a village." In some cases, such as South Naknek, enough residents migrated to Wasilla and Anchorage that the Village Council also moved its office. The findings also indicate that commercial fishery activity is variable, from both natural cycles and regulation. Residents must either leave to find work, or find other sources of income, including welfare and social assistance. Lack of employment in communities ultimately leads to outmigration and community decline (Himes-Cornell and Hoelting 2015; Donkersloot and Carothers 2016).

Finally, decreased engagement in commercial fisheries was an issue for most communities. Some residents sold permits to recover lost income associated with stock declines or market crashes. For example, Port Graham and Port Lions residents sold commercial fishery permits after fish value dropped from the Exxon Valdez oil spill. For others, fisheries declined following cannery closures. In larger communities, such as Dillingham and Kenai, fishermen sold permits because of the high costs of participating in fisheries. In most cases, permits were sold to individuals residing outside of the community and even outside Alaska. The loss of permits and reduced engagement in fisheries increases a community's level of vulnerability, particularly in areas with few economic alternatives where communities have diminished in size (Donkersloot and Carothers 2016).

\section{Discussion}

This ground-truthing exercise which sought to validate quantitative social indices of community vulnerability verified that the quantitative indices were largely consistent with the qualitative data collected from representative communities. However, there were some notable exceptions. Utilization of the capital assets framework confirmed that several factors affecting community vulnerability and well-being are not currently reflected in the quantitative indices and may prove very difficult to quantify in the future. Our findings demonstrate that inclusion of community social capital, policy, 
physical capital (infrastructure), and ecological indicators is integral to a holistic evaluation of community vulnerability and well-being.

The most consistent synergies between the quantitative index scores and ethnographic findings occurred with the commercial and recreational fishing indices, particularly with commercial fishing engagement and reliance. This is likely because respondents discussed fishing in terms of livelihood dependence and reliance, which is directly comparable with the variables included (e.g., as ex-vessel value of commercial catch by residents, number of vessels and permits owned by residents and crew licenses) to develop the fishing indices. These variables appear to accurately reflect fishery participation. There was some inconsistency, however, with the recreational fishing engagement findings in some communities, including Ouzinkie, Port Lions, and Sand Point. The ethnographic data indicated there was less recreational fishing engagement and reliance in these communities than the quantitative indices suggest. For example, Ouzinkie and Port Lions have been experiencing declines in recreational fishing, although residents have charter fishing licenses. Respondents in these communities reported that lodges were for sale and the economic climate has shifted away from recreational fishing. Also, recreational fishing activity in Sand Point may not be as prominent as the quantitative indices suggests since respondents mainly discussed commercial fishing and some were openly hostile to expanding local recreational fishing opportunities.

The subsistence harvesting involvement index was the least robust in representing the importance and extent of subsistence fishing. This is likely due to the quality of secondary data for subsistence harvest. Our analysis of ethnographic data confirmed that all 13 communities participated in subsistence fishing at moderate or high levels, and communities were dependent upon subsistence fishing to supplement their livelihoods while the quantitative indices reflected low subsistence engagement for 11 of the 12 communities with data. This identifies two key lessons from this ground-truthing exercise. First, the quantitative approach is only as good as the data used in the analysis and the subsistence data used to create the subsistence harvesting engagement index has some important limitations (see Note 1 in Himes-Cornell and Kasperski 2016). For instance, data are reported voluntarily and while comprehensive when collected, only a few communities are completely surveyed each year resulting in some communities not having been surveyed since the 1980s. Other times it is unclear or undocumented how many people depend on resources when subsistence harvests are shared within families and entire communities. It is entirely possible that one subsistence fishing permit provides for multiple people, as sharing fish is common within and between fishing community families. Second, the PCFA methodology creates a relative score for all entities included in the analysis so only communities that are relatively more engaged than average will get a score above the mean, even if subsistence harvesting is objectively important to all communities. Therefore, the quantitative indices should always be considered in reference to the other communities included in the analysis, because while several of the visited communities had a low subsistence importance ranking among all Alaska communities, relative to all communities in the United States, these communities would certainly rank highly on subsistence importance (ADF\&G 2000). This potentially different focus of the quantitative and qualitative metrics should not be ignored when comparing across approaches and some metrics may be more useful as relative comparisons across entities while others are more informative as an assessment in absolute terms. 
With regard to nonfishery social indices, the labor force structure and housing characteristics indices appear to be relatively robust, while personal disruption, poverty, and housing disruption are less reliable. It is notable that the social indices appear to be more accurate in larger and more economically diverse communities. For example, the larger fishing communities of Kodiak, Dillingham, and Kenai had low quantitative scores for the poverty and personal disruption indices. This was verified with ethnographic data, as these communities had more diverse economies and job opportunities. However, the quantitative indices typically failed to capture higher rates of personal disruption and poverty in smaller communities heavily dependent upon fishing (i.e., Seldovia, Ouzinkie, Port Lions, Naknek, and South Naknek). These communities did not have a stable work force due to out-migration. They lacked education and economic opportunities, and were reliant on other forms of income such as social security and corporation dividends. In addition, the communities of Port Graham, Ouzinkie, Aleknagik, and South Naknek lacked the secondary data needed to create complete and reliable quantitative indices.

There are challenges to developing social indices that accurately represent community vulnerability. Inconsistencies in the collection of U.S. Census data from smaller communities that are remote and difficult to access, reduce the reliability of indices representing smaller communities in Alaska. The quantitative social indices could be modified to better reflect on-the-ground realities. For example, fishery permit retention, cost of living, migration, stock status, and infrastructure (physical capital) are suitable variables to incorporate, given that these were prominent themes in the communities. Interviewees in all communities mentioned a decline in species such as king salmon or halibut suggesting that ecological indicators such as stock status are relevant to vulnerability evaluations. The quantitative indices also do not capture social or political processes. Our findings demonstrate that smaller communities, such as Port Lions, Naknek, South Naknek, and Port Graham, with higher ranks of vulnerability, demonstrated strong social capital. Conversely, communities such as Kenai and Soldotna experienced conflict between fishing groups. These are significant factors that should be included in social indicator development, given that social capital increases community resilience to events that could alter their socio-economic status whereas conflict weakens their ability to withstand shocks and collectively promote change to improve fisheries (Adger 2010; Cutter, Boruff, and Shirley 2003; Miller et al. 2010). In addition, communities with access to political capital or strong forms of representation, such as BBEDC communities, have more opportunities for engaging in fisheries.

Assumptions about the vulnerability of communities based on secondary data should be carefully evaluated and cross examined with qualitative ethnographic data as several on-the-ground themes emerged from the ground-truthing exercise. Prominent trends across communities include significant reliance upon subsistence resources to supplement livelihoods, high cost of living, out-migration, lack of economic opportunity, and decreased opportunity in commercial fishing. Our finding of heavy reliance on subsistence fishing in all communities is consistent with other research that emphasizes the significance of subsistence fishing activity in Alaska communities (Donkersloot and Carothers 2016; Loring and Gerlach 2009). Also, the issues of permit loss and high costs of fisheries entry has been a common trend since the implementation of limited entry 
and later catch share programs in Alaska (Carothers 2013; Carothers, Lew, and Sepez 2010; Donkersloot and Carothers 2016; Fina 2011; Himes-Cornell and Hoelting 2015; Knapp 2011; Lyons, Carothers, and Reedy 2016). This suggests that indicators for fisheries policy and markets should also be included in evaluations of fishing community vulnerability.

In addition, compromised natural capital, such as reduced fish stocks and pollution, increases community vulnerability; and political and social factors, such as conflict and social capital which may increase or decrease a community's vulnerability, are not reflected in the quantitative indices, yet are common across communities. The capital assets framework captured these factors and provided a practical approach for groundtruthing and evaluating levels of community vulnerability in rural Alaska. This approach helped reveal the importance of social and political capital in evaluations of community vulnerability. It also revealed that communities with lower vulnerability scores for some quantitative indices presented higher qualitative scores of vulnerability based on ethnographic data, or they lacked quantitative secondary data altogether for creating the quantitative social indices.

Our findings demonstrate that practice of developing and validating social indices of community well-being and vulnerability is not a linear process as it requires careful consideration of diverse and complex socio-ecological processes that affect fishing community vulnerability which may not be captured from secondary data alone. As Adger $(2006,274)$ states, "It is important to provide consistent frameworks for measuring vulnerability that provide complimentary quantitative and qualitative insights into outcomes and perceptions of vulnerability." An ideal next step in modifying the vulnerability indices of Alaska fishing communities, to better reflect on the ground realities, will include validation by community members as has been suggested elsewhere (Oulahen et al. 2015).

\section{Conclusion}

Quantitative social indices are useful rapid assessment tools for assessing community vulnerability and well-being provided that they are grounded and modified where necessary. The ground-truthing exercise we present here demonstrates the importance of utilizing both quantitative and qualitative data for developing such indices, similar to suggestions by other scholars (Blount et al. 2015; Lyons, Carothers, and Reedy 2016; Oulahen et al. 2015; Pollnac et al. 2015; Smith et al. 2011; Turner et al. 2003). In our case, there was relatively strong agreement between most quantitative indices and ethnographic data, yet some indices need additional validation, especially in relation to small communities where secondary socio-economic data are not reliable. Furthermore, while each community has unique histories and relationships with resources, ethnographic research indicated that cost of living, lack of employment opportunities, reliance on subsistence resources, loss of fishery permits, and out-migration are central concerns across fishing communities of Alaska affecting their well-being. While some of these sources of vulnerability were reflected in the quantitative indices, such as employment rates and housing costs, the indices could be modified to better reflect socio-economic processes, and the social and political dynamics of fishing communities. Our findings 
demonstrate the need to continue validating and modifying social indicators. Social indicator development is an iterative process as efforts to create and modify indicators continue to evolve. Future efforts should consider adapting the capital assets framework to guide in indicator selection and for mixed methods research, and aid in cross-comparison of case studies of community vulnerability.

\section{Acknowledgments}

We thank Chang Seung and Marysia Szymkowiak of NOAA Fisheries Alaska Fisheries Science Center, and anonymous reviewers, for their comments improving this paper. The findings and conclusions in this study are those of the authors and do not necessarily represent the views of the National Marine Fisheries Service.

\section{Funding}

This research was funded by the NOAA Office of Science and Technology and supported by "Laboratoire d'Excellence" LabexMER (ANR-10-LABX-19) at the European Institute of Marine Sciences (IUEM).

\section{References}

Acheson, J. M. 1988. The lobster gangs of Maine. Hanover, NH: University Press of New England.

ADF\&G. 2000. Subsistence in Alaska: A year 2000 update. division of subsistence. Alaska Department of Fish and Game, Juneau, AK.

Adger, W. N. 2006. Vulnerability. Global Environmental Change 16 (3):268-81.

Adger, W. N. 2010. Social capital, collective action, and adaptation to climate change. In Der klimawandel: Sozialwissenschaftliche perspektiven, ed. M. Voss, 327-45. Wiesbaden, Germany: VS Verlag für Sozialwissenschaften.

Allison, E. H., and F. Ellis. 2001. The livelihoods approach and management of small-scale fisheries. Marine Policy 25 (5):377-88.

Alwang, J., P. B. Siegel, and L. Steen. 2001. Vulnerability: A view from different disciplines. Social protection discussion paper series; No. Sp 0115. Washington, DC: The World Bank.

Bebbington, A. 1999. Capitals and capabilities: A framework for analyzing peasant viability, rural livelihoods and poverty. World Development 27 (12):2021-44.

Bitsch, V. 2005. Qualitative research: A grounded theory example and evaluation criteria. Journal of Agribusiness 23 (1):75-91.

Blaikie, P., T. Cannon, I. Davis, and B. Wisner. 1994. At risk: Natural hazards, people's vulnerability and disasters. London, UK: Routledge.

Blount, B., S. Jacob, P. Weeks, and M. Jepson. 2015. Testing cognitive ethnography: Mixed-methods in developing indicators of well-being in fishing communities. Human Organization 74 (1):1-15.

Bodin, Ö., and B. I. Crona. 2008. Management of natural resources at the community level: Exploring the role of social capital and leadership in a rural fishing community. World Development 36 (12):2763-79.

Boyd, H., and A. Charles. 2006. Creating community-based indicators to monitor sustainability of local fisheries. Ocean \& Coastal Management 49(5-6):237-58.

Carothers, C. 2013. A survey of US halibut IFQ holders: Market participation, attitudes, and impacts. Marine Policy 38:515-22. 
Carothers, C., D. K. Lew, and J. Sepez. 2010. Fishing rights and small communities: Alaska halibut IFQ transfer patterns. Ocean \& Coastal Management 53 (9):518-23.

Clark, W. C., J. Jäger, R. Corell, R. Kasperson, J. J. McCarthy, D. Cash, S. J. Cohen, P. Desanker, N. M. Dickson, P. Epstein, D. H. Guston, J. M. Hall, C. Jaeger, A. Janetos, N. Leary, M. A. Levy. 2000. Assessing Vulnerability to Global Environmental Risks. Discussion Paper, 2000-12, Environment and Natural Resources Program, Belfer Center, August 31.

Colburn, L. L., M. Jepson, C. Weng, T. Seara, J. Weiss, and J. A. Hare. 2016. Indicators of climate change and social vulnerability in fishing dependent communities along the Eastern and Gulf coasts of the United States. Marine Policy 74:323-33.

Cutter, S. L., L. Barnes, M. Berry, C. Burton, E. Evans, E. Tate, and J. Webb. 2008. A place-based model for understanding community resilience to natural disasters. Global Environmental Change 18 (4):598-606.

Cutter, S. L., B. J. Boruff, and W. L. Shirley. 2003. Social vulnerability to environmental hazards. Social Science Quarterly 84 (2):242-61.

DFID. 1999. Sustainable livelihoods guidance sheets. London, UK: Department for International Development.

Donkersloot, R., and C. Carothers. 2016. The graying of the Alaskan fishing fleet. Environment: Science and Policy for Sustainable Development 58 (3):30-42.

Eakin, H., and A. L. Luers. 2006. Assessing the vulnerability of social-environmental systems. Annual Review of Environment and Resources 31 (1):365-94.

Fina, M. 2011. Evolution of catch share management: Lessons from catch share management in the North Pacific. Fisheries 36 (4):164-77.

Gutierrez, N. L., R. Hilborn, and O. Defeo. 2011. Leadership, social capital and incentives promote successful fisheries. Nature 470 (7334):386-9.

Hay, I. 2010. Qualitative research methods in human geography. 3rd ed. Ontario, Canada: Oxford University Press.

Hicks, C. C., A. Levine, A. Agrawal, X. Basurto, S. J. Breslow, C. Carothers, S. Charnley, S. Coulthard, N. Dolsak, J. Donatuto, C. Garcia-Quijano, M. B. Mascia, K. Norman, M. R. Poe, T. Satterfield, K. St. Martin, and P. S. Levin. 2016. Engage key social concepts for sustainability. Science 352 (6281):38-40.

Himes-Cornell, A., and K. Hoelting. 2015. Resilience strategies in the face of short- and longterm change: Out-migration and fisheries regulation in Alaskan fishing communities. Ecology and Society 20 (2):9. doi:10.5751/ES-07074-200209.

Himes-Cornell, A., and S. Kasperski. 2015. Assessing climate change vulnerability in Alaska's fishing communities. Fisheries Research 162:1-11.

Himes-Cornell, A., and S. Kasperski. 2016. Using socioeconomic and fisheries involvement indices to understand Alaska fishing community well-being. Coastal Management 44 (1):36-70.

Himes-Cornell, A., C. Maguire, S. Kasperski, K. Hoelting, and R. Pollnac. 2016. Understanding vulnerability in Alaska fishing communities: A validation methodology for rapid assessment of indices related to well-being. Ocean \& Coastal Management 124:53-65.

Isham, J. 2000. Can investments in social capital improve well-being in fishing communities? A theoretical perspective for assessing the policy options. International institute of fisheries economics and trade. Paper presented at the IIFET, in Oregon State University.

Jacob, S., P. Weeks, B. Blount, and M. Jepson. 2010. Exploring fishing dependence in Gulf Coast communities. Marine Policy 34 (6):1307-14.

Jacob, S., P. Weeks, B. Blount, and M. Jepson. 2013. Development and evaluation of social indicators of vulnerability and resiliency for fishing communities in the Gulf of Mexico. Marine Policy 37:86-95.

Jepson, M., and L. L. Colburn. 2013. Development of social indicators of fishing community vulnerability and resilience in the U.S. Southeast and Northeast regions. NOAA technical memorandum NMFS-F/SPO-129, 64. U.S. Dept. of Commerce.

Jick, T. D. 1979. Mixing qualitative and quantitative methods: Triangulation in action. Administrative Science Quarterly 24 (4):602-11. 
Kent, K., and A. Himes-Cornell. 2016. Making landfall: Linkages between fishing communities and support services. Coastal Management 44 (4):279-94.

Knapp, G. 2011. Local permit ownership in Alaska salmon fisheries. Marine Policy 35 (5):658-66.

Leslie, H. M., Basurto, X. M. Nenadovic, L. Sievanen, K. C. Cavanaugh, J. J. Cota-Nieto, B. E. Erisman, E. Finkbeiner, G. Hinojosa-Arango, M. Moreno-Baez, S. Nagavarapu, S. M. W. Reddy, A. Sánchez-Rodríguez, K. Siegel, J. J. Ulibarria-Valenzuela, A. H. Weaver, and O. Aburto-Oropeza. 2015. Operationalizing the social-ecological systems framework to assess sustainability. Proceedings of the National Academy of Sciences of the United States of America 112 (19):5979-84.

Loring, P. A., and S. C. Gerlach. 2009. Food, culture, and human health in Alaska: An integrative health approach to food security. Environmental Science \& Policy 12 (4):466-78.

Lyons, C., C. Carothers, and K. Reedy. 2016. Means, meanings, and contexts: A framework for integrating detailed ethnographic data into assessments of fishing community vulnerability. Marine Policy 74:341-350.

Marín, A., and F. Berkes. 2010. Network approach for understanding small-scale fisheries governance: The case of the Chilean coastal co-management system. Marine Policy 34 (5):851-8.

Marín, A. S., J. Gelcich, J. C. Castilla, and F. Berkes. 2012. Exploring social capital in Chile's coastal benthic comanagement system using a network approach. Ecology and Society 17 (1):13. doi:10.5751/ES-04562-170113.

Mayunga, J. S. 2007. Understanding and applying the concept of community disaster resilience: A capital-based approach. A draft working paper prepared for the summer academy for social vulnerability and resilience building, 22-28 July 2007, Munich, Germany.

Mclaughlin, P., and T. Dietz. 2008. Structure, agency and environment: Toward an integrated perspective on vulnerability. Global Environmental Change 18 (1):99-111.

Miller, F., Osbahr, H. E. Boyd, F. Thomalla, S. Bharwani, G. Ziervogel, B. Walker, J. Birkmann, S. Van Der Leeuw, J. Rockström, J. Hinkel, T. Downing, C. Folke, and D. Nelson. 2010. Resilience and vulnerability: Complementary or conflicting concepts? Ecology and Society 15 (3):11.

Newman, L., and A. Dale. 2005. Network structure, diversity, and proactive resilience building: A response to Tompkins and Adger. Ecology and Society 10 (1):r2.

Olsson, P., C. Folke, and F. Berkes. 2004. Adaptive comanagement for building resilience in social-ecological systems. Environmental Management 34 (1):75-90.

Oulahen, G., L. Mortsch, K. Tang, and D. Harford. 2015. Unequal vulnerability to flood hazards: "Ground Truthing" a social vulnerability index of five municipalities in Metro Vancouver, Canada. Annals of the Association of American Geographers 105 (3):473-95.

Plummer, R., and J. Fitzgibbon. 2007. Connecting adaptive co-management, social learning, and social capital. In Adaptive co-management: Collaboration, learning, and multi-level governance, ed. D. Armitage, F. Berkes, and N. Doubleday, 38-61. Vancouver, BC: UBC Press.

Pollnac, R. B., S. Abbott-Jamieson, C. Smith, M. L. Miller, P. M. Clay, and B. Oles. 2006. Toward a model for fisheries social impact assessment. Marine Fisheries Review 68 (1-4):118.

Pollnac, R. B., T. Seara, L. L. Colburn, and M. Jepson. 2015. Taxonomy of USA east coast fishing communities in terms of social vulnerability and resilience. Environmental Impact Assessment Review 55:136-43.

Pretty, J. 2003. Social capital and the collective management of resources. Science 302 (5652):1912-4.

Rakodi, C. 1999. A capital assets framework for analysing household livelihood strategies: Implications for policy. Development Policy Review 17 (3):315-42.

Saldana, J. 2009. A coding manual for qualitative researchers. London, UK: Sage Publications Ltd.

Schneider, S. H., S. Semenov, A. Patwardhan, I. Burton, C. H. D. Magadza, M. Oppenheimer, A. B. Pittock, A.Rahman, J. B. Smith, A. Suarez and F. Yamin, 2007. Assessing key vulnerabilities and the risk from climate change. Climate Change 2007: Impacts, Adaptation and Vulnerability. Contribution of Working Group II to the Fourth Assessment Report of the Intergovernmental Panel on Climate Change, ed. by M. L. Parry, O. F. Canziani, J. P. Palutikof, P. J. van der Linden and C. E. Hanson. Cambridge, UK: Cambridge University Press, 779-810. 
Scoones, I. 1998. Sustainable rural livelihoods: A framework for analysis. IDS working paper, 72. Brighton, UK: IDS.

Scoones, I. 2009. Livelihoods perspectives and rural development. The Journal of Peasant Studies $36(1): 171-96$.

Sekhar, N. U. 2007. Social capital and fisheries management: The case of Chilika Lake in India. Environmental Management 39 (4):497-505.

Sepez, J., K. Norman, A. Poole, and B. Tilt. 2006. Fish scales: Scale and method in social science research for North Pacific and West Coast fishing communities. Human Organization 65 (3):280-93.

Smith, S. L., R. B. Pollnac, L. L. Colburn, and J. Olson. 2011. Classification of coastal communities reporting commercial fish landings in the U.S. Northeast Region: Developing and Testing a Methodology Marine Fisheries Review 73 (2):41-61.

Turner, B. L., R. E. Kasperson, P. A. Matson, J. J. Mccarthy, R. W. Corell, L. Christensen, N. Eckley, J. X. Kasperson, A. Luers, M. L. Martello, C. Polsky, A. Pulsipher, and A. Schiller. 2003. A framework for vulnerability analysis in sustainability science. Proceedings of the National Academy of Sciences of the United States of America 100 (14):8074-9. 


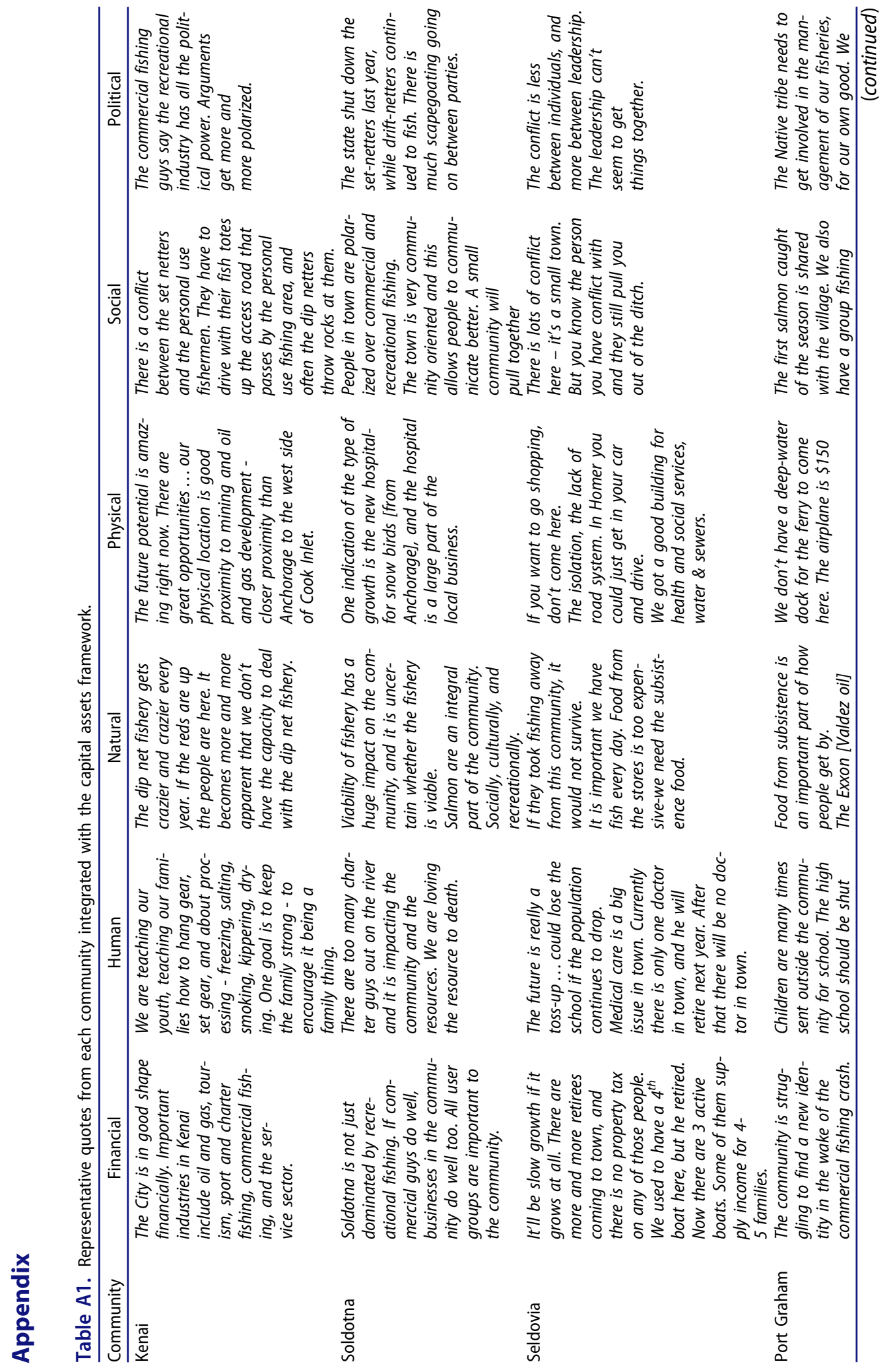




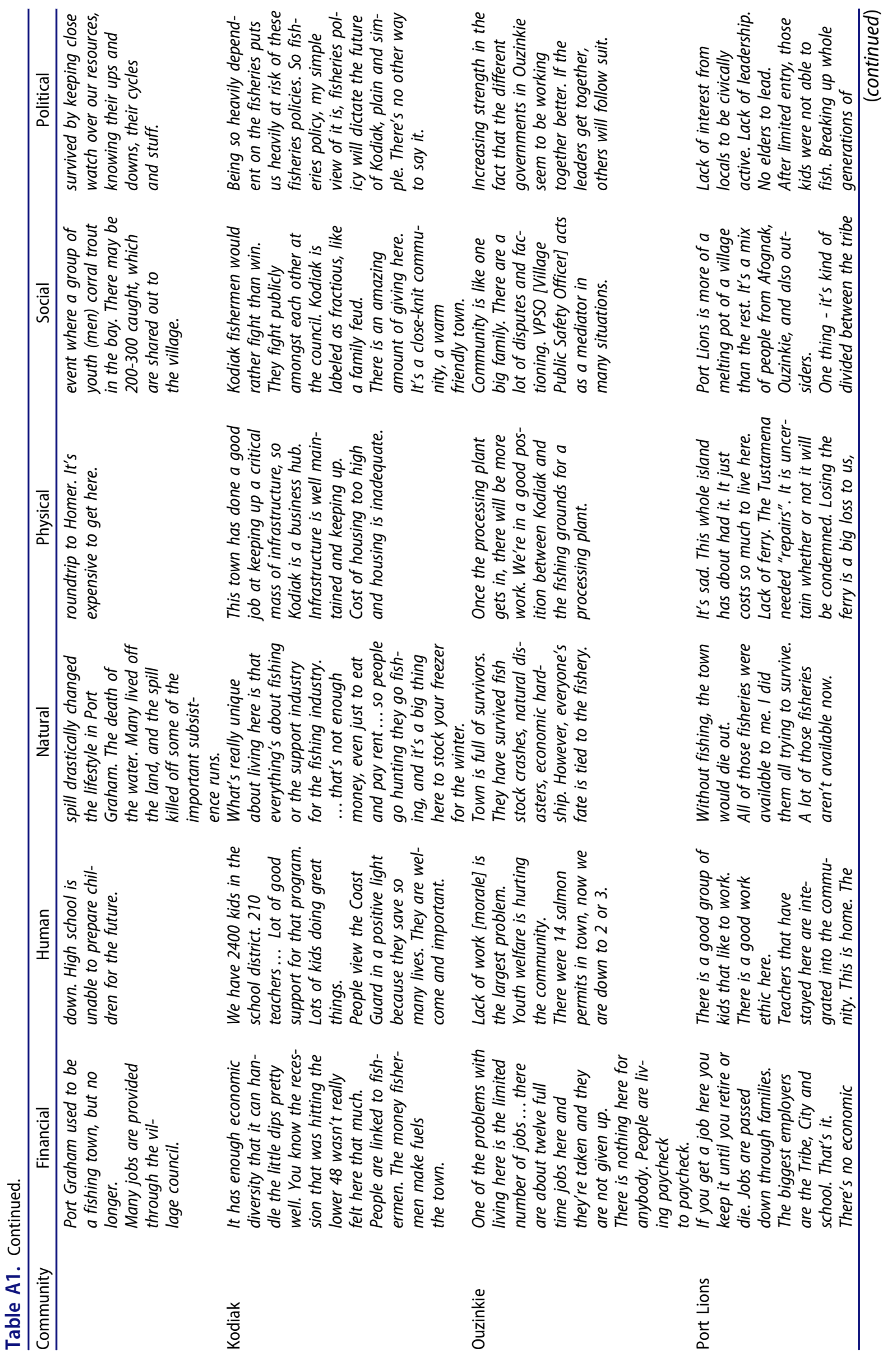




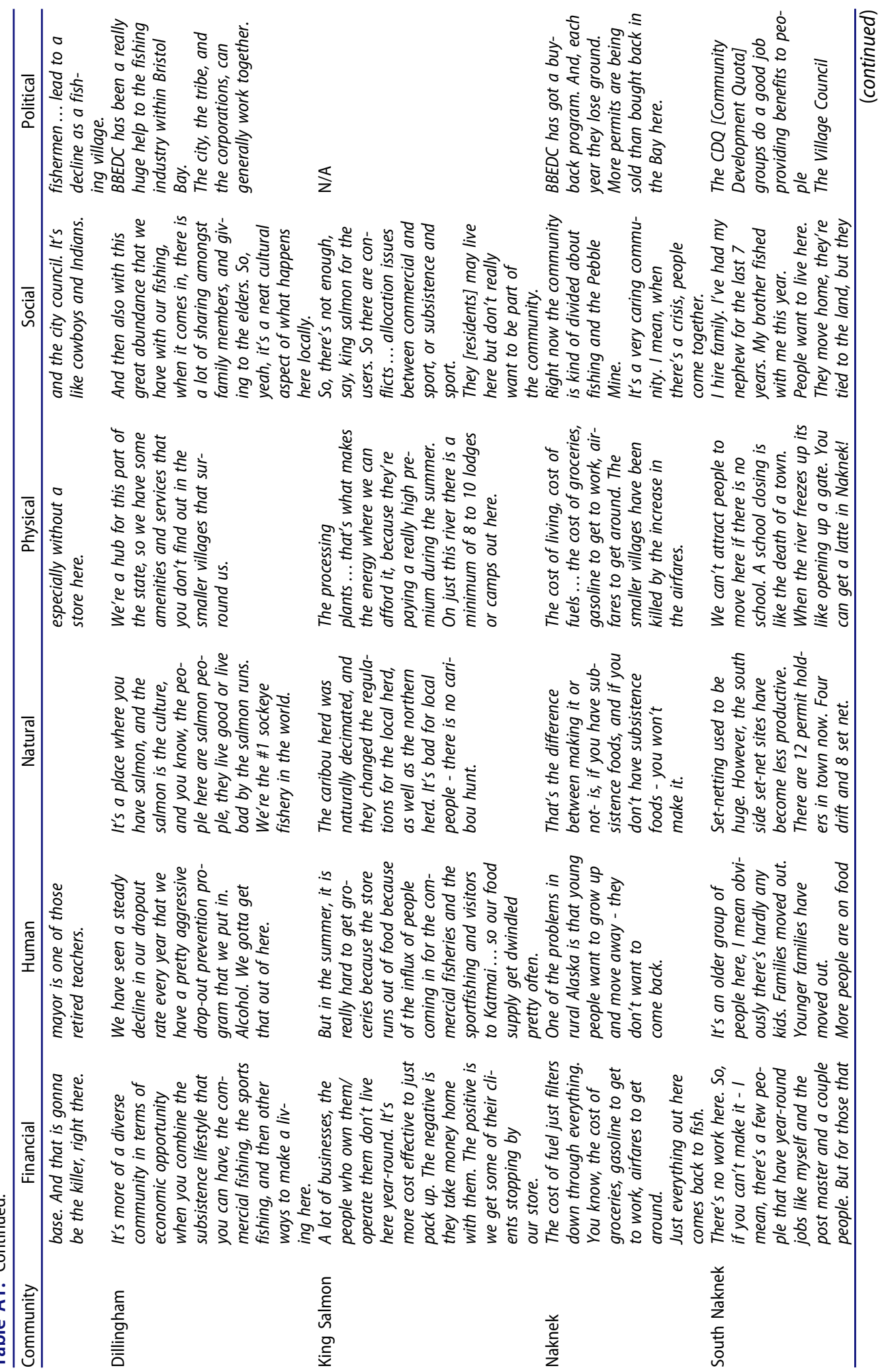




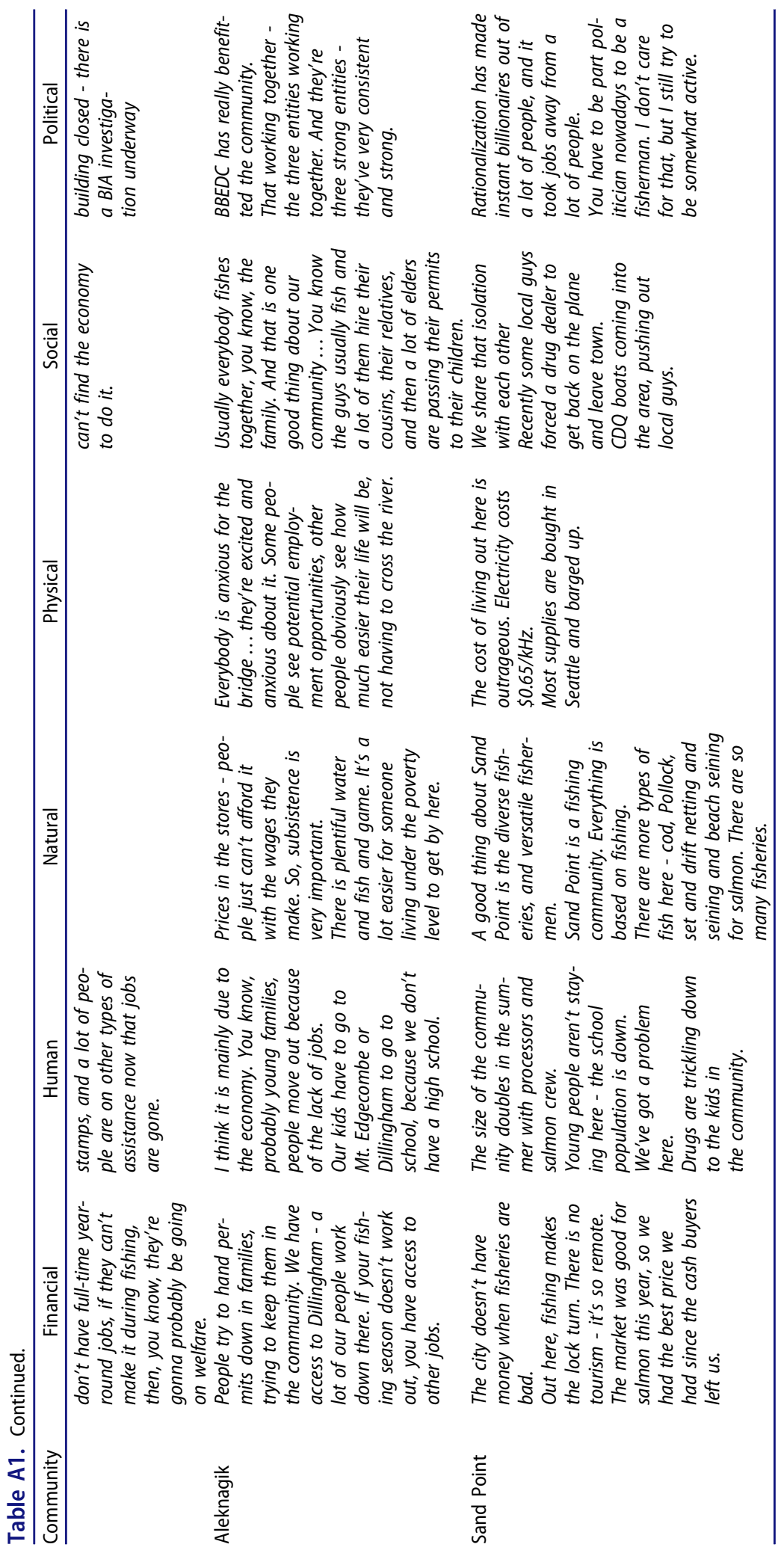

